\title{
Author Correction: Atmospheric transport and deposition of microplastics in a remote mountain catchment
}

Steve Allen (D), Deonie Allen (D), Vernon R. Phoenix, Gaël Le Roux, Pilar Durántez Jiménez, Anaëlle Simonneau,

Stéphane Binet and Didier Galop

Correction to: Nature Geoscience https://doi.org/10.1038/s41561-019-0335-5, published online 15 April 2019.

In the version of this Article originally published, the following text was missing from the Acknowlegements: 'CESBIO OHM Bernadouze weather station is supported by the Observatoire Spatial Régional (CNRS-INSU) and CNES-TOSCA funding was awarded to S. Gascoin. This scientific work was made possible with the logistical support of the ONF (French National Forestry Office) and the support of the inhabitants of the valley'. In addition, ref. 17 was the wrong reference, it should have been 'Gascoin, S. \& Fanise, P. Bernadouze Meteorological Data https://doi.org/10.6096/DV/UQITZ4 (SEDOO OMP, 2018)'. The Article has now been corrected.

Published online: 18 June 2019

https://doi.org/10.1038/s41561-019-0409-4

\section{Author Correction: End-Permian extinction amplified by plume-induced release of recycled lithospheric volatiles}

Michael W. Broadley, Peter H. Barry (D), Chris J. Ballentine (D, Lawrence A. Taylor and Ray Burgess

Correction to: Nature Geoscience https://doi.org/10.1038/s41561-018-0215-4, published online 27 August 2018.

In the version of this Article originally published, the authors concentration of $\mathrm{Cl}, \mathrm{Br}$ and I in the Siberian SCLM were incorrectly reported as ' $0.6-1.5 \times 10^{19}, 1.6-2.7 \times 10^{17}$ and $0.5-1.1 \times 10^{14} \mathrm{~kg}$ ', respectively; the correct values are ' $0.6-1.5 \times 10^{17}, 1.6-2.7 \times 10^{15}$ and $0.5-1.1 \times 10^{13} \mathrm{~kg}$ ' of $\mathrm{Cl}, \mathrm{Br}$ and I, respectively. The partition coefficient of $\mathrm{Cl}$ was also incorrectly stated as ' $1.5 \times 10^{-2}$; the correct value is $1.6 \times 10^{-1}$. In addition, the mass of SCLM in Supplementary Table 1 was incorrectly stated as ' $2.1 \times 10^{21} \mathrm{~kg}$ '; the correct mass is $3.6 \times 10^{20} \mathrm{~kg}$. This has now been amended. The correct values were used for all subsequent calculations throughout the manuscript and therefore these changes have no influence on the original conclusion of the Article. In addition, in Fig. 2a, some data points for crushing Obnazhennaya xenoliths (open red circles) were missing. The figure has now been amended.

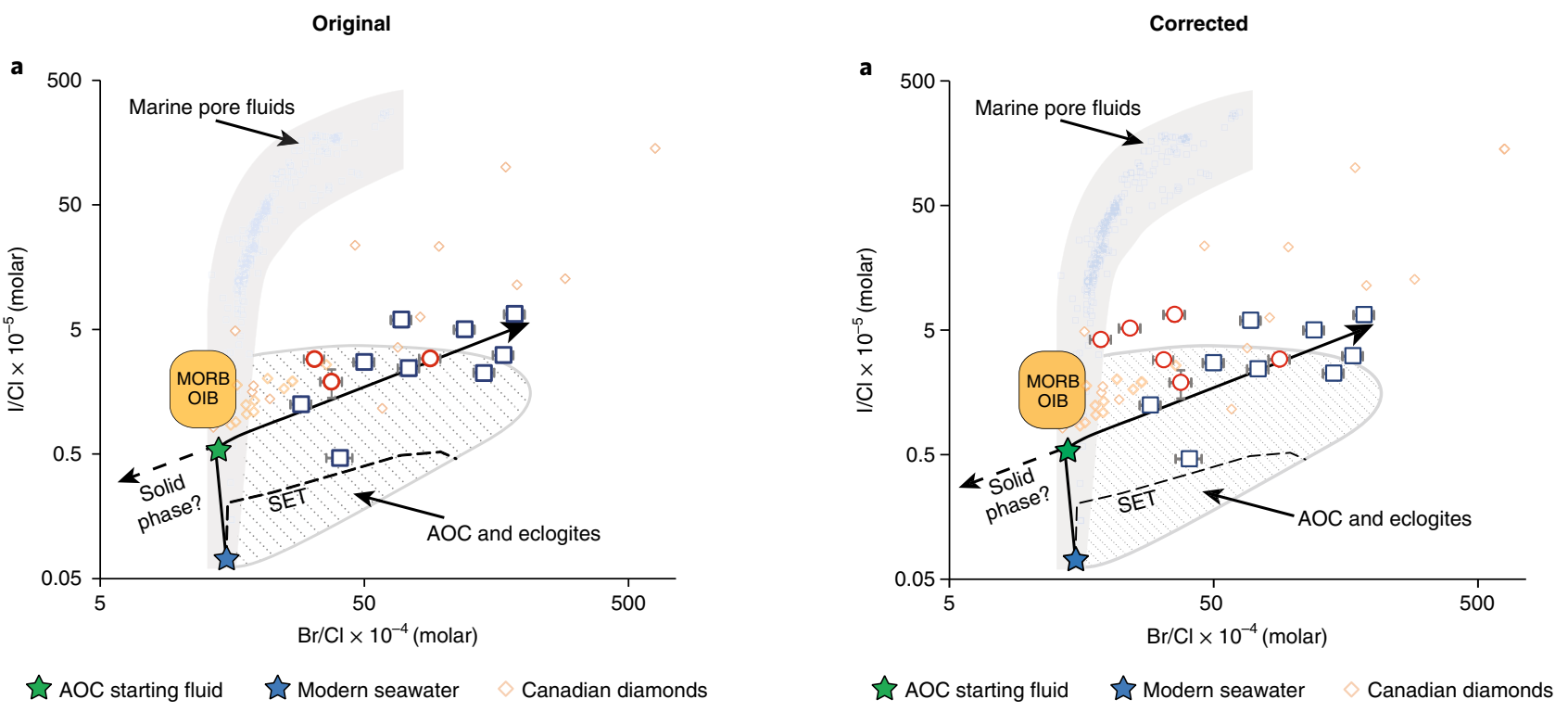

Fig. 2a | Original and corrected. 